\title{
Endovascular Therapy and Ethnic Disparities in Stroke Outcomes
}

\author{
Mehdi Bouslama Leticia C. Rebello Diogo C. Haussen \\ Jonathan A. Grossberg Aaron M. Anderson Samir R. Belagaje \\ Nicolas A. Bianchi Michael R. Frankel Raul G. Nogueira \\ Departments of Neurology and Neurosurgery, Grady Memorial Hospital and Emory \\ University School of Medicine, Atlanta, GA, USA
}

\section{Keywords}

Acute stroke $\cdot$ Cerebral ischemia $\cdot$ Thrombectomy $\cdot$ Ischemic stroke $\cdot$ Cerebrovascular procedures · Quality and outcomes

\begin{abstract}
Background and Purpose: Ethnic disparities in stroke are well described, with a higher incidence of disability and increased mortality in Blacks versus Whites. We sought to compare the clinical outcomes between those ethnic groups after stroke endovascular therapy (ET). Methods: We performed a retrospective review of the prospectively acquired Grady Endovascular Stroke Outcomes Registry between September 1, 2010 and September 30, 2015. Patients were dichotomized into two groups - Caucasians and African-Americans - and matched for age, pretreatment glucose level, and baseline National Institutes of Health Stroke Scale (NIHSS) score. Baseline characteristics as well as procedural and outcome parameters were compared. Results: Out of the 830 patients treated with ET, 308 pairs of patients $(n=616)$ underwent primary analysis. African-Americans were younger $(p<0.01)$, had a higher prevalence of hypertension $(p<0.01)$ and diabetes $(p=0.04)$, and had higher Alberta Stroke Program Early CT Score values $(p=0.03)$ and shorter times to treatment $(p=0.01)$. Blacks more frequently had Medicaid coverage and less private insurance (29.6 vs. $11.4 \%$ and 41.5 vs. $60.3 \%$, respectively, $p<0.01$ ). The remaining baseline characteristics, including baseline NIHSS score and CT perfusion-derived ischemic core volumes, were well balanced. There were no differences in the overall distribution of 90-day modified Rankin scale scores $(p=0.28)$, rates of successful reperfusion ( 84.7 vs. $85.7 \%, p=0.91$ ), good outcomes ( 49.1 vs. $44 \%, p=0.24$ ), or parenchymal hematomas (6.5 vs. $6.8 \%, p=1.00$ ). Blacks had lower 90 -day mortality rates (18
\end{abstract}

M. Bouslama and L.C. Rebello contributed equally to this work.

Raul G. Nogueira, MD

Emory University School of Medicine

49 Jesse Hill Jr. Drive, SE, Room \#333

Atlanta, GA 30303 (USA)

E-Mail raul.g.nogueira @ emory.edu 
vs. $24.6 \%, p=0.04$ ) in univariate analysis, which persisted as a nonsignificant trend after adjustment for potential confounders (OR $0.52,95 \% \mathrm{Cl} 0.26-1.03, p=0.06$ ). Conclusions: Despite unique baseline characteristics, African-Americans treated with ET for large vessel occlusion strokes have similar outcomes as Caucasians. Greater availability of ET may diminish the ethnic/racial disparities in stroke outcomes.

(C) 2018 S. Karger AG, Basel

\section{Introduction}

Disparities in stroke disability and mortality between different ethnic groups are well described, with stroke being twice as common and associated with higher mortality rates in Blacks compared to Whites $[1,2]$. This also holds true when it comes to geographic location. Patients residing in the "stroke belt" of the USA have $40 \%$ more stroke-related deaths compared to those in the rest of the country [3]. Despite the overall decline in stroke-related deaths for adults suffering a stroke across racial groups, age-adjusted rates remain higher within the African-American community [4]. This might be due to several factors such as access to care, socioeconomic status, social habits, genetics, etc. [1,5]. Over the past few years, stroke care has progressed tremendously, with proven efficacy of endovascular therapy (ET) and the widening of the scope of its indications. However, this promising therapy has been mostly validated in populations of Caucasian dominance [6-10]. The differences in stroke etiology and outcomes among ethnic groups as well as the fact that racial minorities are projected to constitute more than $40 \%$ of the US population by 2050 [5] hasten the need to further evaluate this therapy in other ethnic groups.

Here, we compare the functional outcomes and mortality between Blacks and Whites undergoing stroke ET at a large-volume tertiary care center in the "stroke belt."

\section{Methods}

Patient Selection and Measures of Outcomes

We reviewed our prospectively collected Grady Endovascular Stroke Outcomes Registry between September 1, 2010 and September 30, 2015 to identify patients with large vessel occlusions who underwent intra-arterial therapy with documented ethnic information. Race-ethnicity information was based on selfidentification [11]. Patients with incomplete information or identifying as Hispanic, Asian, mixed, or belonging to other ethnicities were excluded. Patients were then categorized into two groups: (1) Caucasian/White and (2) African-American/Black.

The two groups were matched for age, baseline National Institutes of Health Stroke Scale (NIHSS) score, and pretreatment glucose level [12]. Baseline characteristics and demographics as well as procedural parameters were collected. The primary outcome measure was the overall degree of disability as measured by the modified Rankin scale (mRS) at 90 days. The secondary endpoints included the rates of good outcomes (defined as 90-day mRS scores of 0-2) and successful reperfusion as defined by a modified Thrombolysis in Cerebral Infarction score of $2 b-3$. The safety endpoints included the rates of any parenchymal hematoma $(\mathrm{PH})$ as per the European Cooperative Acute Stroke Study criteria [13] and 90-day mortality.

Imaging Protocol, CT Perfusion Parameters, and Final Infarct Volume Calculation

All patients underwent an institutional imaging protocol, including noncontrast CT with or without CT angiography and CT perfusion. The imaging acquisition parameters were the same for all patients included in the study. CT perfusion was evaluated with a fully automated software environment (RAPID version 4.5.0; iSchemaView, Menlo Park, CA, USA). The ischemic tissue volume (ischemic core) was defined by a voxel relative cerebral blood flow $<30 \%$ of that of normal tissues. The total hypoperfused volume was defined by $>6$ s delay in the time to maximum tissue residue function and a penumbral volume of at-risk tissue defined by the difference between total hypoperfused and ischemic core tissue estimates [14]. 
Follow-up imaging included noncontrast CT or MRI documenting the final infarct volume within 5 days of treatment. Diffusion-weighted imaging was preferentially utilized if MRI was obtained within the first $72 \mathrm{~h}$ of the stroke, and fluid-attenuated inversion recovery was used if MRI was performed between 3 and 5 days. Edema producing sulcal effacement was not excluded. Hemorrhagic transformation was incorporated into the final infarct volume whenever present. Final infarct volumes were measured following export of raw DICOM data to the Fiji release of the ImageJ software platform using a standardized, semiautomated approach (http://imagej.nih.gov/ij/) [14].

\section{Matching Methodology}

A matching method based on weighted Euclidean distances was used to obtain a pair of subjects considered to be the nearest neighbors in a three-dimensional space of age, baseline NIHSS score, and pretreatment glucose levels, as previously described [12]. The distance between each White-Black pair was computed using the \%FIND_NEIGHBORS Macro in SAS ${ }^{\circledR}$ University Edition (SAS Institute, Cary, NC, USA). Each Black patient was matched with the nearest White patient (having the smallest Euclidean distance).

After matching, the distribution of Euclidean distances was studied to identify outliers and a threshold was determined as follows: threshold $=\mathrm{Q} 75+1.5 \times(\mathrm{Q} 75-\mathrm{Q} 25)$, where Q25 and Q75 are the 25th and 75th percentile, respectively. Pairs with distances greater than the threshold were considered extreme values at the tail of the distribution and eliminated from further consideration.

\section{Statistical Analysis}

The Shapiro-Wilk test was used to assess the normality of the variables. Continuous variables were reported as mean \pm standard deviation if normally distributed or median [interquartile range] if nonparametric. Categorical variables were reported as proportions. Between groups, comparisons for continuous/ ordinal variables were made with the Student $t$ test, the Mann-Whitney U test, or ANOVA, as appropriate. Categorical variables were compared by the $\chi^{2}$ test or the Fisher exact test, as appropriate [15]. The overall distribution of 90-day mRS scores was compared between groups (shift in disability levels) using the van Elteren test. Ordinal regression was computed for ORs to assess the association between ethnicity and mRS score. Multivariate logistic regression analyses for predictors of good outcomes, successful reperfusion, any $\mathrm{PH}$, and mortality were performed for variables at the 0.1 level of significance on univariate analysis (stepwise backward LR method). Significance was set at $p<0.05$ and all $p$ values were two-sided.

Statistical analysis was performed using IBM ${ }^{\circledR}$ SPSS $^{\circledR}$ Statistics 23 (IBM, Armonk, NY, USA) and SAS ${ }^{\circledR}$ University Edition. Graphical output was obtained from MATLAB ${ }^{\circledR}$ (MathWorks, Natick, MA, USA).

\section{Results}

\section{Inclusion/Exclusion}

Of the 830 patients treated over the study period, 49 were excluded because they were identified as belonging to other ethnicities (Hispanic [ $n=21]$, Asian [ $n=17]$, and others [ $n=$ 11]). Of the remaining 781 patients, 440 (56\%) were categorized as Caucasian/White and $341(44 \%)$ as African-America/Black.

The two groups of patients were matched for age, baseline glucose levels, and baseline NIHSS score. Patients with missing information regarding these three parameters $(n=20)$ were excluded and did not undergo the matching process. After matching, 332 pairs of WhiteBlack patients were generated, of which 24 had an Euclidean distance higher than the preset threshold and 308 underwent primary analysis (Fig. 1).

\section{Baseline Characteristics}

African-Americans were younger ( $61.51 \pm 13.98$ vs. $64.68 \pm 12.75$ years, $p<0.01)$, had higher rates of hypertension ( 81.2 vs. $68.5 \%, p<0.01$ ) and diabetes ( 28.9 vs. $21.8 \%, p=0.04$ ), and had higher baseline Alberta Stroke Program Early CT Score values (8 [7-9] vs. 7 [6-8], $p=0.03)$ and shorter times from last known normal to groin puncture (300 [236-530] vs. 391 


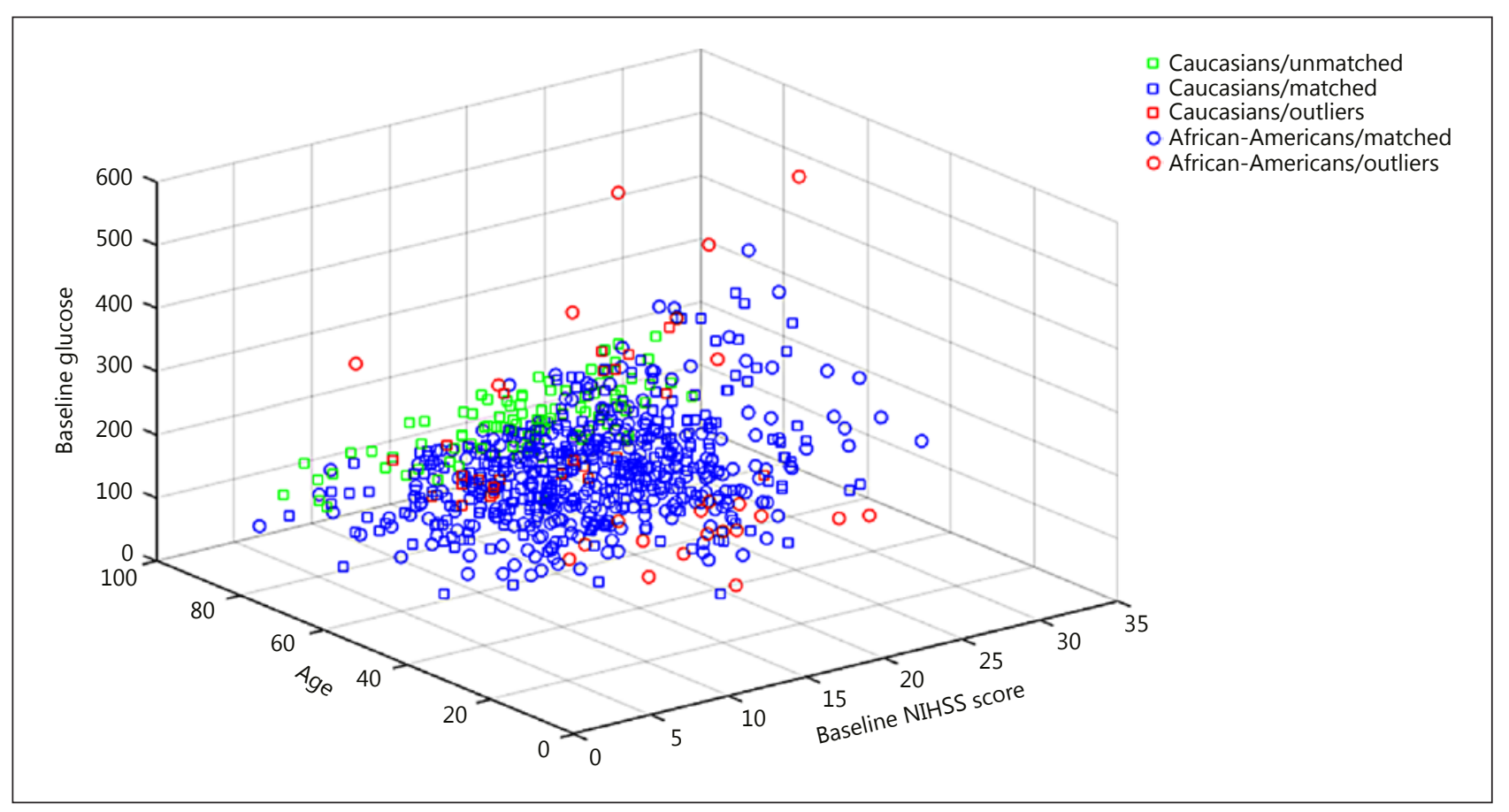

Fig. 1. Distribution of individual subjects after matching based on their baseline National Institutes of Health Stroke Scale (NIHSS) score, age, and glucose level.

[248-461] min, $p=0.01$ ) compared to Whites. Blacks were less often transferred from an outside hospital ( 40.3 vs. $83.4 \%, p<0.01$ ) (Table 1 ).

Insurance coverage was different between both ethnic groups $(p<0.01)$, with Blacks having more Medicaid and less private coverage (29.6 vs. $11.4 \%$ and 41.5 vs. $60.3 \%$, respectively, $p<0.01$ ).

\section{Efficacy and Safety Outcomes}

Univariate Analysis. The mRS score distribution (OR 1.16, 95\% CI 0.86-1.54, $p=0.28$ ) and the rates of good outcomes ( 49.1 vs. $44 \%, p=0.15$ ) at 90 days were similar across the two groups. African-American patients had lower 90 -day mortality rates (18 vs. $24.6 \%, p=0.04$ ) compared to Caucasians (Table 2; Fig. 2). There were no statistically significant differences in the rates of successful reperfusion (modified Thrombolysis in Cerebral Infarction score $2 \mathrm{~b}-3,84.7$ vs. $87.7 \%, p=1.00$ ) or PH ( 6.5 vs. $6.8 \%, p=1.00$ ). The final infarct volumes were 42.06 [10.96-61.59] vs. 35.43 [23.13-72.47] $\mathrm{cm}^{3}, p=0.05$. Sensitivity analysis looking at outcome differences according to sex showed that there were no differences in 90-day good outcomes or mortality in the male group between Blacks and Whites ( 53.3 vs. $44.8 \%, p=0.13$, and 21.3 vs. $26.4 \%, p=0.03$, respectively). In the female group, 90 -day good outcomes were comparable ( 44.4 vs. $43.5 \%, p=0.89$ ), while African-American women had lower mortality rates (13.5 vs. $22.9 \%, p=0.049$ ).

Multivariate Analysis. After adjusting for confounders, there was a nonsignificant trend for lower 90-day mortality in Blacks compared to Whites (adjusted OR 0.52, 95\% CI 0.26$1.03, p=0.06$ ). There was no significant association between ethnicity and 90-day good outcomes, successful reperfusion, or PH. The predictors of 90-day mortality, good outcome, successful reperfusion, and PH are summarized in Table 3. 
Table 1. Baseline characteristics as well as imaging and procedural parameters

\begin{tabular}{|c|c|c|c|}
\hline & $\begin{array}{l}\text { Caucasians } \\
(n=308)\end{array}$ & $\begin{array}{l}\text { African-Americans } \\
(n=308)\end{array}$ & $p$ value \\
\hline Age, years $^{1}$ & $64.68 \pm 12.75$ & $61.51 \pm 13.98$ & $<0.01$ \\
\hline Glucose, $\mathrm{mg} / \mathrm{dL}^{1}$ & 117 [103-125] & 123 [104-133] & 0.12 \\
\hline Baseline NIHSS score ${ }^{1}$ & $18.04 \pm 5.42$ & $18.59 \pm 6.34$ & 0.62 \\
\hline Male sex & $173(56.2 \%)$ & 163 (52.9\%) & 0.47 \\
\hline Hypertension & $211(68.5 \%)$ & $250(81.2 \%)$ & $<0.01$ \\
\hline Dyslipidemia & $111(36 \%)$ & $125(40.6 \%)$ & 0.28 \\
\hline Atrial fibrillation & $100(29.9 \%)$ & $100(29.9 \%)$ & 0.54 \\
\hline Diabetes & $67(21.8 \%)$ & $89(28.9 \%)$ & 0.04 \\
\hline Smoking & $69(22.4 \%)$ & $60(19.5 \%)$ & 0.43 \\
\hline Health insurance & & & $<0.01$ \\
\hline Uninsured & $32(10.4 \%)$ & $32(10.6 \%)$ & \\
\hline Medicaid & $35(11.4 \%)$ & $89(29.6 \%)$ & \\
\hline Medicare & $53(17.3 \%)$ & $53(17.6 \%)$ & \\
\hline Private & $185(60.3 \%)$ & $125(41.5 \%)$ & \\
\hline Veterans Affairs & $2(0.7 \%)$ & $2(0.7 \%)$ & \\
\hline Transfers & $257(83.4 \%)$ & $124(40.3 \%)$ & $<0.01$ \\
\hline Low-density lipoprotein, mg/dL & $91.23 \pm 39.09$ & $93.18 \pm 41.20$ & 0.93 \\
\hline International normalized ratio & $1[1-1.1]$ & $1[1-1.1]$ & 0.56 \\
\hline Systolic blood pressure, mm Hg & $138.88 \pm 28.18$ & $154.18 \pm 39.57$ & 0.74 \\
\hline \multicolumn{4}{|l|}{ Occlusion site } \\
\hline Anterior cerebral artery & $1(0.3 \%)$ & $4(1.3 \%)$ & 0.37 \\
\hline Middle cerebral artery M1 & $128(41.6 \%)$ & $137(44.5 \%)$ & 0.52 \\
\hline Middle cerebral artery M2 & $39(12.7 \%)$ & $51(16.6 \%)$ & 0.21 \\
\hline Middle cerebral artery M3 & $6(1.9 \%)$ & $5(1.6 \%)$ & 1.00 \\
\hline ICA terminus & $41(13.3 \%)$ & $53(17.2 \%)$ & 0.22 \\
\hline Extracranial ICA & $7(2.3 \%)$ & $8(2.6 \%)$ & 1.00 \\
\hline Vertebrobasilar & $32(10.4 \%)$ & $27(8.8 \%)$ & 0.50 \\
\hline Tandem occlusion & $54(17.5 \%)$ & $23(7.5 \%)$ & $<0.01$ \\
\hline ASPECTS & $7[6-8]$ & $8[7-9]$ & 0.03 \\
\hline CT perfusion & 137 (44.5\%) & 119 (38.6\%) & 0.17 \\
\hline $\mathrm{rCBF}<30 \%, \mathrm{~cm}^{3}$ & 31 [6.7-44.9] & $26.9[5.9-40.3]$ & 0.26 \\
\hline $\mathrm{T}_{\max }>6 \mathrm{~s}, \mathrm{~cm}^{3}$ & $161.7[118.2-214.4]$ & $163.1[113-265.6]$ & 0.44 \\
\hline Intravenous tPA & $137(44.8 \%)$ & 137 (44.8\%) & 1.00 \\
\hline \multicolumn{4}{|l|}{ Procedural parameters } \\
\hline LKN puncture & 391 [248-461] & $300[236-530]$ & 0.01 \\
\hline Procedural length & $70[48-105.5]$ & $73[51-112]$ & 0.23 \\
\hline Monitored anesthesia care & $183(59.6 \%)$ & $175(57.2 \%)$ & 0.57 \\
\hline Stent retriever & $207(67.2 \%)$ & $184(59.7 \%)$ & 0.07 \\
\hline Stroke etiology & & & 0.34 \\
\hline Cardioembolism & 145 (47.1\%) & 145 (47.1\%) & \\
\hline Large vessel atherosclerosis & $54(17.5 \%)$ & $47(15.3 \%)$ & \\
\hline ICAD & $23(7.5 \%)$ & $26(8.4 \%)$ & \\
\hline Undetermined & $74(24 \%)$ & $86(27.9 \%)$ & \\
\hline Other & $12(3.9 \%)$ & $4(1.3 \%)$ & \\
\hline
\end{tabular}

Data are presented as mean \pm standard deviation, median [interquartile range], or $n$ (\%). ASPECTS, Alberta Stroke Program Early CT Score; ICA, internal carotid artery; ICAD, intracranial atherosclerotic disease; INR, international normalized ratio; LDL, low-density lipoprotein; LKN, last known normal; NIHSS, National Institutes of Health Stroke Scale; $\mathrm{rCBF}$, relative cerebral blood flow; $\mathrm{T}_{\max }$, time to maximum tissue residue function; tPA, tissue plasminogen activator. ${ }^{1}$ The two groups were matched for these variables. 
Table 2. Outcomes

\begin{tabular}{lccc}
\hline & $\begin{array}{l}\text { Caucasians } \\
(n=308)\end{array}$ & $\begin{array}{l}\text { African-Americans } \\
(n=308)\end{array}$ & $p$ value \\
\hline Reperfusion & & & 0.91 \\
mTICI 2b-3 & $264(85.7 \%)$ & $261(84.7 \%)$ & 0.87 \\
mTICI 3 & $119(38.6 \%)$ & $115(37.3 \%)$ & 1 \\
Any PH & $21(6.8 \%)$ & $20(6.5 \%)$ & 0.05 \\
Final infarct volume, $\mathrm{cm}^{3}$ & $35.43[23.13-72.47]$ & $42.06[10.96-61.59]$ & \\
90 -day mRS score & $(n=293)$ & $(n=283)$ & \\
0 & $16(5.5 \%)$ & $22(7.8 \%)$ & \\
1 & $62(21.2 \%)$ & $69(17 \%)$ & \\
2 & $51(17.4 \%)$ & $39(13.8 \%)$ & 0.24 \\
3 & $44(15 \%)$ & $23(8.1 \%)$ & 0.04 \\
4 & $28(9.6 \%)$ & $251(18 \%)$ & $139(49.1 \%)$ \\
6 & $20(6.8 \%)$ & $251(18 \%)$ & \\
\hline Mortality & $72(24.6 \%)$ & $129(44 \%)$ & \\
\hline
\end{tabular}

Data are presented as $n(\%)$ or median [interquartile range]. mRS, modified Rankin scale; mTICI, modified Thrombolysis in Cerebral Infarction; PH, parenchymal hematoma.

Fig. 2. Functional outcome at 90 days according to the score on the modified Rankin scale (mRS).

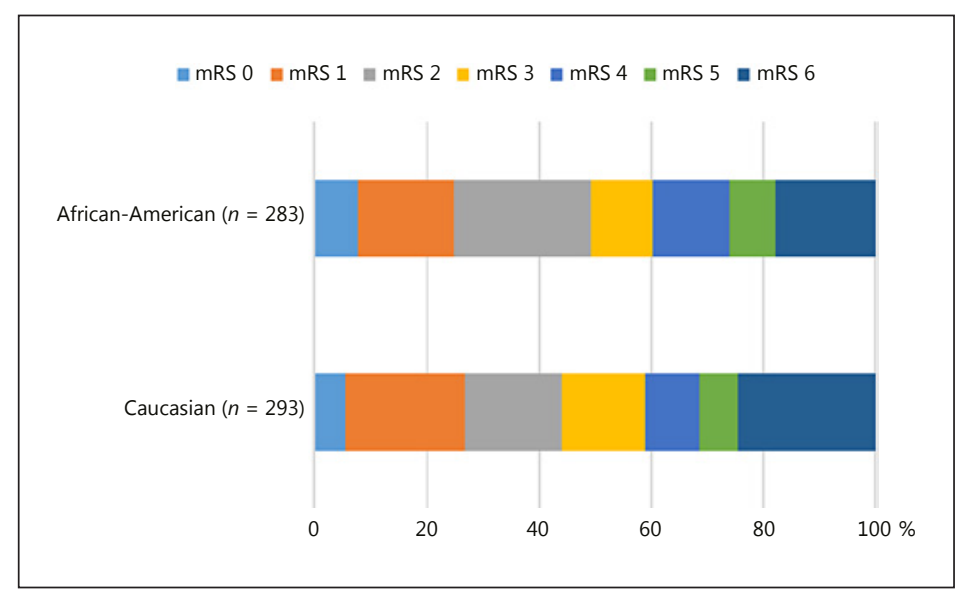

\section{Discussion}

Our data from a large biracial population suggest that there are no clinical or procedural outcomes disparities between Whites and Blacks undergoing ET for large vessel occlusion acute stroke. Specifically, we demonstrated a similar distribution of 90-day mRS scores with comparable rates of successful reperfusion, good outcomes, and PH. Notably, we did not observe any mortality increase in Blacks versus Whites as previously reported in other large cohort studies. This suggest that aggressive stroke intervention might attenuate some of the mortality disparities in stroke. Our results remained stable after adjustment for potential confounders in multivariate analysis.

Blacks are historically known to have a higher stroke incidence and mortality compared to Whites $[1,2,4]$. This might be explained by several factors, including the higher prevalence 
Table 3. Predictors of 90-day mortality, good outcome (mRS score $0-2$ ), successful reperfusion (mTICI 2b-3), and PH

\begin{tabular}{lccc}
\hline & OR & $95 \%$ CI & $p$ value \\
\hline 90-day mortality & & & \\
Age & 1.05 & $1.02-1.08$ & 0.02 \\
Glucose & 1.01 & $1.00-1.02$ & 0.006 \\
Baseline NIHSS score & 1.20 & $1.11-1.29$ & $<0.001$ \\
Ethnicity (Black) & 0.52 & $0.26-1.03$ & 0.06 \\
International normalized ratio & 2.53 & $1.06-6.05$ & 0.03 \\
ASPECTS & 0.78 & $0.63-0.97$ & 0.02 \\
Monitored anesthesia care & 0.33 & $0.16-0.68$ & 0.002 \\
mTICI 2b-3 & 0.22 & $0.10-0.48$ & $<0.001$ \\
Any PH & 5.51 & $1.84-16.46$ & 0.002 \\
90-day mRS score 0-2 & & & \\
Age & 0.96 & $0.94-0.98$ & $<0.001$ \\
Glucose & 0.99 & $0.98-0.99$ & 0.03 \\
Baseline NIHSS score & 0.90 & $0.86-0.95$ & $<0.001$ \\
International normalized ratio & 0.51 & $0.24-1.11$ & 0.09 \\
ASPECTS & 1.59 & $1.32-1.90$ & $<0.001$ \\
Procedure length & 0.99 & $0.98-0.99$ & 0.01 \\
Monitored anesthesia care & 2.31 & $1.36-3.92$ & 0.002 \\
mTICI 2b-3 & 4.22 & $1.88-9.49$ & $<0.001$ \\
Any PH & 0.20 & $0.05-0.80$ & 0.02 \\
mTICI 2b-3 & & & \\
Smoking & 1.99 & $1.01-3.92$ & 0.045 \\
Monitored anesthesia care & 1.72 & $1.06-2.78$ & 0.03 \\
Stent retriever & 2.05 & $1.26-3.32$ & 0.004 \\
Any PH & & & \\
Baseline NIHSS score & 1.11 & $1.03-1.19$ & 0.006 \\
\hline
\end{tabular}

ASPECTS, Alberta Stroke Program Early CT Score; mRS, modified Rankin scale; mTICI, modified Thrombolysis in Cerebral Infarction; NIHSS, National Institutes of Health Stroke Scale; PH, parenchymal hematoma.

of vascular risk factors such as hypertension, diabetes, smoking, or excessive alcohol use among this patient population [1]. In the Northern Manhattan Stroke Study, hypertension and diabetes were more prevalent among the Black and Hispanic groups, while atrial fibrillation was more common in Whites [11]. Our analysis confirms historic data, with Blacks having strokes at a younger age as well as a higher prevalence of hypertension and diabetes. Interestingly, stroke etiologies were comparable between groups, in contrast to previous studies showing that Whites had more cardioembolic strokes while Blacks tended to have more lacunar or small vessel infarcts [16]. This finding is likely related to a selection bias since this is primarily an ET cohort, but it could also have been introduced during the matching process.

Another factor that could explain historic disparities in stroke outcomes between ethnic groups is that minorities have less access to medical care [1, 5]. In fact, Kumar et al. [5] demonstrated that Blacks were less likely to be treated with thrombolysis (adjusted OR 0.84, 95\% CI $0.76-0.92, p<0.001$ ) and intra-arterial therapy (OR 0.73, 95\% CI 0.58-0.91, $p=0.01$ ). The authors hypothesized that this could be due to delays in symptoms recognition and presentation outside the treatment window, a higher prevalence of contraindications in AfricanAmericans, or a systematic bias in healthcare delivery. Similarly, a recent analysis of the Get With The Guidelines-Stroke data revealed that emergency medical services transport differed by race/ethnicity, with minorities less likely to use them [17]. Moreover, Kissela et al. [1] found that Blacks were more likely to have Medicaid coverage compared to Whites, which 
may have contributed to the inequalities in access to treatment. This held true in our analysis, with African-Americans having twice as high Medicaid coverage and less private insurance compared to Caucasians. However, a recent analysis of 279 patients from the Reasons for Geographic and Racial Differences in Stroke cohort showed that underutilization of healthcare after stroke did not explain the poorer long-term outcomes in African-Americans [18], and thus the answer regarding the precise causes of these differences remains elusive.

Clinical trials performed in 2015 have proved the superiority of ET over intravenous recombinant tissue plasminogen activator in the treatment of large vessel occlusion acute ischemic stroke [6-10], with growing potential and expanding indications including mild strokes [19], large core infarcts [20], distal occlusions (including middle cerebral artery M2 [21] and beyond [22]), as well as patients presenting late in the therapeutic window with the recent positive results of the DAWN trial [23]. However, the current evidence for ET has predominantly been obtained from populations of Caucasian dominance. In fact, AfricanAmericans represented only $11.2 \%$ of the interventional arm in SWIFT PRIME [6] and presumably an even lower proportion of the recruited patients in the other trials. The differences in stroke etiology and outcomes among ethnic groups and the fact that racial minorities are projected to constitute more than $40 \%$ of the US population by 2050 [5] hasten the need to better understand these discrepancies and further evaluate ET in other populations.

Our matched cohort shows that African-Americans equally benefit from ET, with almost half of the patients achieving good outcomes at 90 days and a trend towards lower mortality rates. Blacks had shorter times to treatment, which is explained by the fact that they were more likely to present directly to the emergency department (compared to Whites, who were more commonly transferred) due to the location of our facility within the city and the population demographic it primarily serves. Another intriguing finding is that African-Americans tended to have larger final infarct volumes despite having a younger age, similar infarct burden on presentation, and similar reperfusion rates, which may be explained by worse collateral recruitment and differences in stroke risk factors/pathogenesis [24]. Also, as mentioned above, other factors such as underutilization of poststroke rehabilitation services [25] and secondary stroke prevention medications given insurance status could explain our outcomes.

Our study has several limitations mostly inherent to its retrospective design. As ET was considered our standard of care for the entire duration of the study, we did not have a medically treated control population that would have allowed us to measure treatment effects per ethnic group. Moreover, we did not automatically record those who did not qualify for ET to be able to measure treatment frequency. Additionally, our results might have been different had we used a different study design or matching variables. Our analysis was also limited to a biracial cohort and by having insurance coverage as the sole measure of socioeconomic status.

\section{Conclusions}

Despite unique baseline characteristics, African-Americans treated with ET for large vessel occlusion strokes have similar outcomes as Caucasians. Greater availability of ET may diminish the ethnic/racial disparities in stroke outcomes.

\section{Statement of Ethics}

This study was approved by the Emory University institutional review board. 


\section{Disclosure Statement}

M. Bouslama, L.C. Rebello, D.C. Haussen, J.A. Grossberg, A.M. Anderson, S.R. Belagaje, N.A. Bianchi, and M.R. Frankel have no disclosures. R.G. Nogueira: Stryker Neurovascular (TREVO 2 trial principal investigator, DAWN trial principal investigator), Covidien (SWIFT and SWIFT PRIME Steering Committee, STAR Trial Core Lab), and Penumbra (3-D Separator Trial Executive Committee).

\section{References}

1 Kissela B, Schneider A, Kleindorfer D, Khoury J, Miller R, Alwell K, Woo D, Szaflarski J, Gebel J, Moomaw C, Pancioli A, Jauch E, Shukla R, Broderick J: Stroke in a biracial population: the excess burden of stroke among blacks. Stroke 2004;35:426-431.

2 Ottenbacher KJ, Campbell J, Kuo YF, Deutsch A, Ostir GV, Granger CV: Racial and ethnic differences in postacute rehabilitation outcomes after stroke in the United States. Stroke 2008;39:1514-1519.

3 Howard G, Howard VJ, Katholi C, Oli MK, Huston S: Decline in US stroke mortality: an analysis of temporal patterns by sex, race, and geographic region. Stroke 2001;32:2213-2220.

4 Mozaffarian D, Benjamin EJ, Go AS, Arnett DK, Blaha MJ, Cushman M, Das SR, de Ferranti S, Despres JP, Fullerton HJ, Howard VJ, Huffman MD, Isasi CR, Jimenez MC, Judd SE, Kissela BM, Lichtman JH, Lisabeth LD, Liu S, Mackey RH, Magid DJ, McGuire DK, Mohler ER 3rd, Moy CS, Muntner P, Mussolino ME, Nasir K, Neumar RW, Nichol G, Palaniappan L, Pandey DK, Reeves MJ, Rodriguez CJ, Rosamond W, Sorlie PD, Stein J, Towfighi A, Turan TN, Virani SS, Woo D, Yeh RW, Turner MB: Heart disease and stroke statistics - 2016 update: a report from the American Heart Association. Circulation 2016;133:e38-e360.

5 Kumar N, Khera R, Pandey A, Garg N: Racial differences in outcomes after acute ischemic stroke hospitalization in the United States. J Stroke Cerebrovasc Dis 2016;25:1970-1977.

6 Saver JL, Goyal M, Bonafe A, Diener HC, Levy EI, Pereira VM, Albers GW, Cognard C, Cohen DJ, Hacke W, Jansen O, Jovin TG, Mattle HP, Nogueira RG, Siddiqui AH, Yavagal DR, Baxter BW, Devlin TG, Lopes DK, Reddy VK, du Mesnil de Rochemont R, Singer OC, Jahan R; SWIFT PRIME Investigators: Stent-retriever thrombectomy after intravenous t-PA vs. t-PA alone in stroke. N Engl J Med 2015;372:2285-2295.

7 Campbell BC, Mitchell PJ, Kleinig TJ, Dewey HM, Churilov L, Yassi N, Yan B, Dowling RJ, Parsons MW, Oxley TJ, Wu TY, Brooks M, Simpson MA, Miteff F, Levi CR, Krause M, Harrington TJ, Faulder KC, Steinfort BS, Priglinger M, Ang T, Scroop R, Barber PA, McGuinness B, Wijeratne T, Phan TG, Chong W, Chandra RV, Bladin CF, Badve M, Rice H, de Villiers L, Ma H, Desmond PM, Donnan GA, Davis SM: Endovascular therapy for ischemic stroke with perfusion-imaging selection. N Engl J Med 2015;372:1009-1018.

8 Jovin TG, Chamorro A, Cobo E, de Miquel MA, Molina CA, Rovira A, San Roman L, Serena J, Abilleira S, Ribo M, Millan M, Urra X, Cardona P, Lopez-Cancio E, Tomasello A, Castano C, Blasco J, Aja L, Dorado L, Quesada H, Rubiera M, Hernandez-Perez M, Goyal M, Demchuk AM, von Kummer R, Gallofre M, Davalos A: Thrombectomy within 8 hours after symptom onset in ischemic stroke. N Engl J Med 2015;372:2296-2306.

9 Goyal M, Demchuk AM, Menon BK, Eesa M, Rempel JL, Thornton J, Roy D, Jovin TG, Willinsky RA, Sapkota BL, Dowlatshahi D, Frei DF, Kamal NR, Montanera WJ, Poppe AY, Ryckborst KJ, Silver FL, Shuaib A, Tampieri D, Williams D, Bang OY, Baxter BW, Burns PA, Choe H, Heo JH, Holmstedt CA, Jankowitz B, Kelly M, Linares G, Mandzia JL, Shankar J, Sohn SI, Swartz RH, Barber PA, Coutts SB, Smith EE, Morrish WF, Weill A, Subramaniam S, Mitha AP, Wong JH, Lowerison MW, Sajobi TT, Hill MD; ESCAPE Trial Investigators: Randomized assessment of rapid endovascular treatment of ischemic stroke. N Engl J Med 2015;372:1019-1030.

10 Berkhemer OA, Fransen PS, Beumer D, van den Berg LA, Lingsma HF, Yoo AJ, Schonewille WJ, Vos JA Nederkoorn PJ, Wermer MJ, van Walderveen MA, Staals J, Hofmeijer J, van Oostayen JA, Lycklama à Nijeholt GJ, Boiten J, Brouwer PA, Emmer BJ, de Bruijn SF, van Dijk LC, Kappelle LJ, Lo RH, van Dijk EJ, de Vries J, de Kort PL, van Rooij WJ, van den Berg JS, van Hasselt BA, Aerden LA, Dallinga RJ, Visser MC, Bot JC, Vroomen PC, Eshghi O, Schreuder TH, Heijboer RJ, Keizer K, Tielbeek AV, den Hertog HM, Gerrits DG, van den Berg-Vos RM, Karas GB, Steyerberg EW, Flach HZ, Marquering HA, Sprengers ME, Jenniskens SF, Beenen LF, van den Berg R, Koudstaal PJ, van Zwam WH, Roos YB, van der Lugt A, van Oostenbrugge RJ, Majoie CB, Dippel DW; MR CLEAN Investigators: A randomized trial of intraarterial treatment for acute ischemic stroke. N Engl J Med 2015;372: 11-20.

11 Sacco RL, Boden-Albala B, Abel G, Lin IF, Elkind M, Hauser WA, Paik MC, Shea S: Race-ethnic disparities in the impact of stroke risk factors: the Northern Manhattan Stroke Study. Stroke 2001;32:1725-1731.

12 Mandava P, Kalkonde YV, Rochat RH, Kent TA: A matching algorithm to address imbalances in study populations: application to the National Institute of Neurological Diseases and Stroke Recombinant Tissue Plasminogen Activator acute stroke trial. Stroke 2010;41:765-770.

13 Hacke W, Kaste M, Fieschi C, Toni D, Lesaffre E, von Kummer R, Boysen G, Bluhmki E, Hoxter G, Mahagne MH, et al: Intravenous thrombolysis with recombinant tissue plasminogen activator for acute hemispheric stroke. The European Cooperative Acute Stroke Study (ECASS). JAMA 1995;274:1017-1025. 
14 Dehkharghani S, Bammer R, Straka M, Albin LS, Kass-Hout O, Allen JW, Rangaraju S, Qiu D, Winningham MJ, Nahab F: Performance and predictive value of a user-independent platform for CT perfusion analysis: threshold-derived automated systems outperform examiner-driven approaches in outcome prediction of acute ischemic stroke. AJNR Am J Neuroradiol 2015;36:1419-1425.

15 Pearce N: Analysis of matched case-control studies. BMJ 2016;352:1969.

16 Markus HS, Khan U, Birns J, Evans A, Kalra L, Rudd AG, Wolfe CD, Jerrard-Dunne P: Differences in stroke subtypes between black and white patients with stroke: the South London Ethnicity and Stroke Study. Circulation 2007;116:2157-2164.

17 Mochari-Greenberger H, Xian Y, Hellkamp AS, Schulte PJ, Bhatt DL, Fonarow GC, Saver JL, Reeves MJ, Schwamm LH, Smith EE: Racial/ethnic and sex differences in emergency medical services transport among hospitalized US stroke patients: analysis of the national Get With The Guidelines-Stroke registry. J Am Heart Assoc 2015; 4:e002099.

18 Roth DL, Sheehan OC, Huang J, Rhodes JD, Judd SE, Kilgore M, Kissela B, Bettger JP, Haley WE: Medicare claims indicators of healthcare utilization differences after hospitalization for ischemic stroke: race, gender, and caregiving effects. Int J Stroke 2016;11:928-934.

19 Haussen DC, Bouslama M, Grossberg JA, Anderson A, Belagage S, Frankel M, Bianchi N, Rebello LC, Nogueira RG: Too good to intervene? Thrombectomy for large vessel occlusion strokes with minimal symptoms: an intention-to-treat analysis. J Neurointerv Surg 2017;9:917-921.

20 Rebello LC, Bouslama M, Haussen DC, Dehkharghani S, Grossberg JA, Belagaje S, Frankel MR, Nogueira RG: Endovascular treatment for patients with acute stroke who have a large ischemic core and large mismatch imaging profile. JAMA Neurol 2017;74:34-40.

21 Sarraj A, Sangha N, Hussain MS, Wisco D, Vora N, Elijovich L, Goyal N, Abraham M, Mittal M, Feng L, Wu A, Janardhan V, Nalluri S, Yoo AJ, George M, Edgell R, Shah RJ, Sitton C, Supsupin E, Bajgur S, Denny MC, Chen PR, Dannenbaum M, Martin-Schild S, Savitz SI, Gupta R: Endovascular therapy for acute ischemic stroke with occlusion of the middle cerebral artery M2 segment. JAMA Neurol 2016;73:1291-1296.

22 Grossberg JA, Rebello LC, Haussen DC, Bouslama M, Bowen M, Winningham M, Schindler KM, Doppelheuer S, Frankel MR, Nogueira RG: Beyond large vessel occlusion strokes: distal occlusion thrombectomy (abstract). Stroke 2017;48:ATP11.

23 Late breaking abstracts. Eur Stroke J 2017;2:477-495.

24 Rebello LC, Bouslama M, Haussen DC, Grossberg JA, Dehkharghani S, Anderson A, Belagaje SR, Bianchi NA, Grigoryan M, Frankel MR, Nogueira RG: Stroke etiology and collaterals: atheroembolic strokes have greater collateral recruitment than cardioembolic strokes. Eur J Neurol 2017;24:762-767.

25 Mayer-Oakes SA, Hoenig H, Atchison KA, Lubben JE, De Jong F, Schweitzer SO: Patient-related predictors of rehabilitation use for community-dwelling older Americans. J Am Geriatr Soc 1992;40:336-342. 